\title{
Atmospheric radiocarbon during the Younger Dryas: production, ventilation, or both?
}

\author{
Olivier Marchal ${ }^{\mathrm{a}, *}$, Thomas F. Stocker ${ }^{\mathrm{a}}$, Raimund Muscheler ${ }^{\mathrm{b}}$ \\ a Climate and Environmental Physics, Physics Institute, University of Bern, Sidlerstrasse 5, CH-3012 Bern, Switzerland \\ b Department of Surface Waters, EAWAG, Überlandstrasse 133, P.O. Box 611, CH-8600 Dübendorf, Switzerland
}

Received 16 August 2000; received in revised form 5 December 2000; accepted 13 December 2000

\begin{abstract}
A new reconstruction of past atmospheric $\Delta^{14} \mathrm{C}\left(\Delta^{14} \mathrm{C}_{\mathrm{atm}}\right)$ based on Polish lake varved sediments has suggested that previous $\Delta^{14} \mathrm{C}_{\mathrm{atm}}$ values (e.g. from the Cariaco basin record) for the beginning of the Younger Dryas cold event (YD) are overestimates and that the $\Delta{ }^{14} \mathrm{C}_{\mathrm{atm}}$ rise at the $\mathrm{YD}$ onset could only be due to changes in atmospheric ${ }^{14} \mathrm{C}$ production $\left(P_{\mathrm{C}-14}\right)$. This result would have profound climatic implications, for the $\mathrm{YD}$ is a paradigm example of abrupt climate change which is usually thought to have been triggered by a reduction in the northward heat flux by the Atlantic thermohaline circulation. Here we examine results from a large number of simulations (300) based on a zonally averaged ocean circulation model, to constrain the effect on $\Delta{ }^{14} \mathrm{C}_{\mathrm{atm}}$ of $P_{\mathrm{C}-14}$ changes during the $\mathrm{YD}$ as reconstructed from a Greenland ice core record of ${ }^{10} \mathrm{Be}$ flux. Our results suggest that the scatter in the lake data set is too large to exclude the probable change in deep ocean ventilation at the onset of the YD. By contrast, the model fit to the higher $\Delta^{14} \mathrm{C}_{\mathrm{atm}}$ levels throughout the YD detected in the marine record is generally better when a substantial decrease in deep ocean ventilation is simulated. The early $\Delta^{14} \mathrm{C}_{\mathrm{atm}}$ drawdown that initiated during the first half of the $\mathrm{YD}$, however, could entirely be due to production changes. If this was the case, the drawdown would not reflect an increasing formation of North Atlantic Intermediate Water or Southern Ocean water, as previously suggested. The rapid $\Delta^{14} \mathrm{C}_{\mathrm{atm}}$ rise at the YD onset documented in the marine record, however, remains unexplained. (C) 2001 Elsevier Science B.V. All rights reserved.
\end{abstract}

Keywords: paleoatmosphere; Younger Dryas; C-14/C-13

\section{Introduction}

The Younger Dryas cold event (YD; between $12700 \pm 100 \mathrm{yr} \mathrm{BP}$ and $11550 \pm 70 \mathrm{yr} \mathrm{BP}$ in the GRIP ice core, central Greenland; [1]) is the most

\footnotetext{
* Corresponding author. Fax: +41-31-631-8742;

E-mail: marchal@climate.unibe.ch
}

recent and best investigated of the abrupt climatic changes that recurred on the millennial time scales in the circum North Atlantic during the last glacial period (e.g. [2]). Although the climate conditions prior to the YD (e.g. Milankovitch forcing and ice sheet configuration) are quite different from the modern ones, the YD is an example of past climatic shift that is used to assess models of climate dynamics, such as those employed to examine the potential of future climate change [3-5]. 

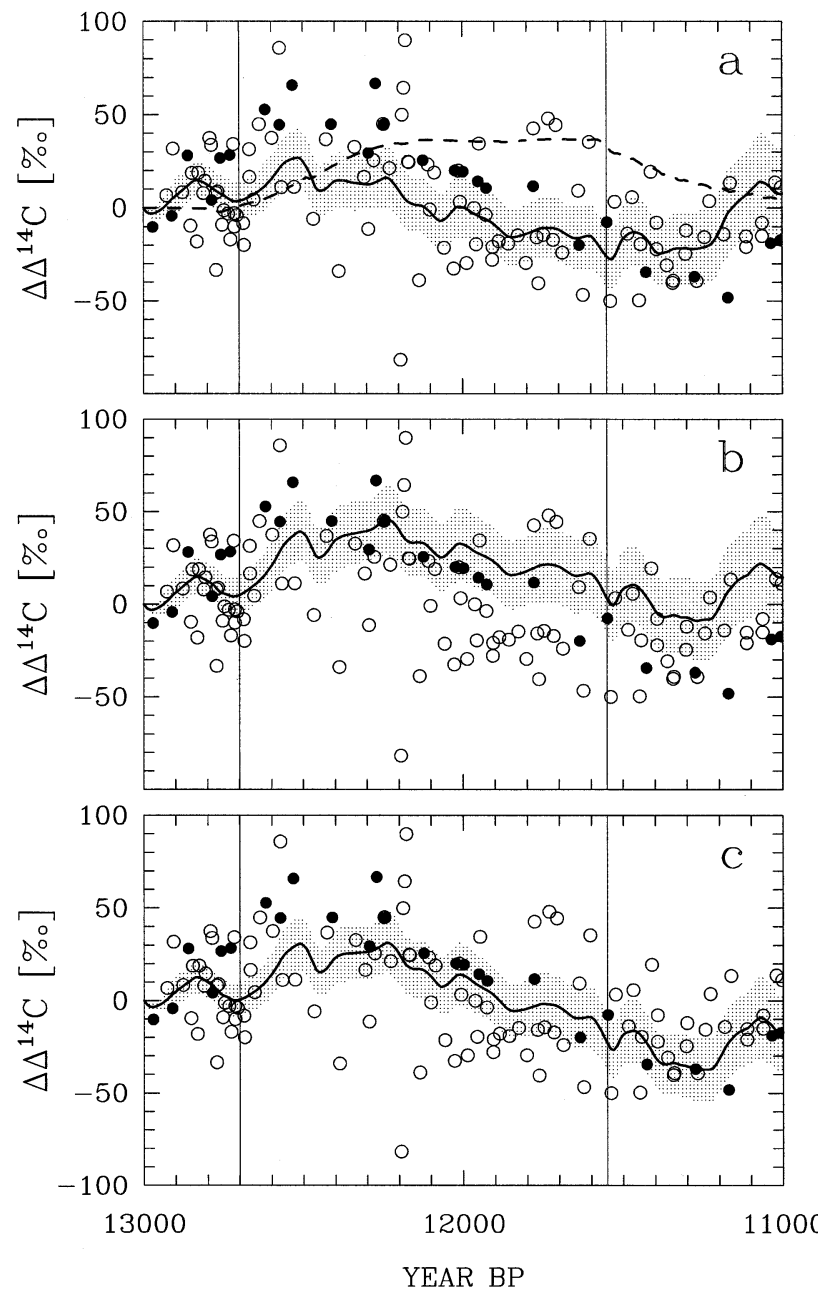

CONSTANT THC
$\&$
VARIABLE $\mathrm{P}_{\mathrm{C}-14}$

VARIABLE THC

$\&$

VARIABLE $\mathrm{P}_{\mathrm{C}-\mathbf{1 4}}$

VARIABLE THC

\&

VARIABLE $\mathrm{P}_{\mathrm{C}-14}$ WITH TREND

Fig. 1. Anomalies of atmospheric $\Delta^{14} \mathrm{C}\left(\Delta^{14} \mathrm{C}_{\mathrm{atm}}\right)$ between 13 and $11 \mathrm{kyr}$ BP based on ${ }^{14} \mathrm{C}$ ages and varve ages from the Cariaco basin ( ; data from Hughen et al. [17]) and from lakes Gosciaz and Perespilno ( $\bigcirc$; data from Goslar et al. [22]), and $\Delta^{14} C_{a t m}$ anomalies simulated by the model. The Cariaco basin chronology (in good agreement with the GISP2 chronology of Alley et al. [19] between $\sim 15$ and $9 \mathrm{kyr} \mathrm{BP}$; [17]) has been adjusted to the GRIP time scale of Johnsen et al. [2], taken here as the reference time scale (for details see [10]). Thus, new $\Delta^{14} \mathrm{C}$ values from the Cariaco basin record were calculated from the original ${ }^{14} \mathrm{C}$ ages (corrected for an average measured reservoir age of $420 \mathrm{yr}$ ) and the adjusted varve ages [50]. We made no adjustment to the Polish lake chronologies (concordant with the GRIP chronology of Johnsen et al. [1] during the YD; [22]). The observed anomalies are computed with respect to the $\Delta^{14} \mathrm{C}_{\mathrm{atm}}$ value at $13 \mathrm{kyr} \mathrm{BP}$, estimated at $162 \%$ (from the Cariaco basin record). a: $\Delta^{14} \mathrm{C}_{\mathrm{atm}}$ anomalies simulated with variable $\mathrm{THC}$ and constant production of atmospheric ${ }^{14} \mathrm{C}\left(P_{\mathrm{C}-14}\right)$ (dashed line), and mean $\Delta^{14} \mathrm{C}_{\mathrm{atm}}$ anomalies from 100 model experiments with constant THC and variable $P_{\mathrm{C}-14}$ (solid line). Each experiment is characterized by a different random selection of $P_{\mathrm{C}-14}$ between 17 and $11 \mathrm{kyr}$ BP consistent with the $P_{\mathrm{C}-14}$ reconstruction based on the Greenland ${ }^{10} \mathrm{Be}$ record (Fig. 2). b: Mean $\Delta^{14} \mathrm{C}_{\mathrm{atm}}$ anomalies from 100 model experiments with variable THC and variable $P_{\mathrm{C}-14}$ (solid line). c: Mean $\Delta^{14} \mathrm{C}_{\mathrm{atm}}$ anomalies from 100 model experiments with variable THC and variable $P_{\mathrm{C}-14}$ characterized by a trend of -0.7 relative units $(30 \mathrm{kyr})^{-1}$ (solid line). The shaded area in a-c illustrates one standard deviation of $\Delta^{14} \mathrm{C}_{\mathrm{atm}}$ for all the experiments. The two vertical lines in each panel denote the onset and termination of the YD as dated in the GRIP ice core [1]. 
The usual hypothesis to explain the YD cooling is a temporary reduction in the Atlantic thermohaline circulation (THC) and associated northward heat flux, caused by the discharge of low-density glacial meltwater in the northern North Atlantic [6]. Virtually all the coupled ocean circulation-atmosphere models used so far to simulate a YDtype event apply a surface freshwater perturbation in this basin in order to trigger a slowdown of the THC and a cold phase at high northern latitudes $[3,4,7-10]$.

The reconstruction of atmospheric $\Delta^{14} \mathrm{C}$ $\left(\Delta^{14} C_{a t m}\right)$ could constrain the changes in deep ocean ventilation and in the associated THC during the YD. Radionuclides like ${ }^{14} \mathrm{C}$ (half-life of $5730 \mathrm{yr})$ and ${ }^{10} \mathrm{Be}\left(1.5 \times 10^{6} \mathrm{yr}\right)$ are produced through the interaction of cosmic ray particles with the Earth's atmosphere. The production of cosmogenic nuclides is thus modulated by the intensity of the heliomagnetic and geomagnetic fields (e.g. [11]). Radiocarbon is oxidized to ${ }^{14} \mathrm{CO}_{2}$, which is taken up during terrestrial photosynthesis and dissolved in the surface ocean. The ${ }^{14} \mathrm{C}$-laden waters are transported to the ocean's interior essentially during deep water formation [12]. Since the time required to ventilate the whole ocean volume is on the order of $1 \mathrm{kyr}$, a large fraction of ${ }^{14} \mathrm{C}$ decays in the deep sea [12]. The mean rate of oceanic ventilation influences therefore the atmospheric $\Delta^{14} \mathrm{C}$, with high rates imparting low $\Delta{ }^{14} \mathrm{C}_{\mathrm{atm}}$ and vice versa (e.g. [8]). ${ }^{10} \mathrm{Be}$, on the other hand, is quickly attached to submicron particles and removed from the atmosphere on a time scale of 1-2 yr, chiefly through precipitation [13]. The records of ${ }^{10} \mathrm{Be}$ concentration from polar ice cores are used to estimate past changes in the production of cosmogenic nuclides (e.g. [14]).

Several paleoclimate records document a $\Delta{ }^{14} C_{a t m}$ increase at the onset of the YD [15-18]. The varved sediment core PL07-56PC from the Cariaco basin, in the southern Caribbean Sea, provides one of the best temporal resolutions of this increase (filled circles in Fig. 1; data from Hughen et al. [17]). Both the onset and termination of the YD in this core are very well defined through the gray scale record and the varve chronology (based on annual layer counting from the gray scale record) agrees with the time scale of
Alley et al. [19] for the GISP2 ice core (central Greenland) [17]. The $\Delta^{14} \mathrm{C}_{\mathrm{atm}}$ increase documented in the Cariaco basin record amounts to $\sim 50-70 \%$ (Fig. 1). The same record also provides one of the best resolutions of the subsequent $\Delta{ }^{14} \mathrm{C}_{\mathrm{atm}}$ drawdown (Fig. 1), which was previously identified through ${ }^{14} \mathrm{C}$ datings of fossil corals [20] and of high-resolution dated lake sediments [16]. This drawdown initiated during the first half of the YD and persisted throughout the cold climatic episode (Fig. 1). It corresponds to one of the longest plateaus detected so far in the ${ }^{14} \mathrm{C}$ age-calendar age relationship [21].

Goslar et al. [22] reported recently a new reconstruction of $\Delta^{14} \mathrm{C}_{\mathrm{atm}}$ during the YD (open circles in Fig. 1). This reconstruction is based on ${ }^{14} \mathrm{C}$ ages of annually laminated sediments from two Polish lakes, Lake Gosciaz and Lake Perespilno. Even though the $\Delta^{14} \mathrm{C}$ values calculated from these ages exhibit some scatter, the Polish lake $\Delta^{14} \mathrm{C}$ record suggests that previous reconstructions, including the one from the Cariaco basin, overestimate $\Delta^{14} \mathrm{C}_{\mathrm{atm}}$ during the first half of the YD (Fig. 1). Goslar et al. [22] then used an ocean box model to simulate $\Delta{ }^{14} \mathrm{C}_{\mathrm{atm}}$ for that period, keeping constant the deep ocean ventilation and prescribing a variable atmospheric ${ }^{14} \mathrm{C}$ production $\left(P_{\mathrm{C}-14}\right)$. The production changes during the $\mathrm{YD}$ were constrained from the geomagnetic field intensity data of Tric et al. [23] and the production model of Lal [24]. Goslar et al. [22] concluded, from their model calculations, that the $\Delta{ }^{14} \mathrm{C}_{\mathrm{atm}}$ values during the first half of the YD documented in the Polish lake record can be entirely explained by changes in $P_{\mathrm{C}-14}$. That is, the radiocarbon evidence would not point to a declining deep ocean ventilation at the onset of the YD. Clearly, this conclusion challenges the THC hypothesis which is able to explain many aspects of the cold climate event and deserves further examination.

In this paper we extend our previous $\Delta{ }^{14} \mathrm{C}_{\mathrm{atm}}$ simulation during a YD-type event based on a zonally averaged ocean circulation model [10], to include a variable $P_{\mathrm{C}-14}$ determined from the best reconstruction currently available. Extensive sensitivity tests on reconstructed $P_{\mathrm{C}-14}$ values with constant and variable THC strength are con- 
ducted. Their results are compared directly to the marine and lake $\Delta^{14} \mathrm{C}$ records in order to examine the conclusion of Goslar et al. [22]. The model experiments with variable THC strength are all forced with the same freshwater perturbation at the surface in the North Atlantic. This perturbation leads to a cold phase at high northern latitudes whose duration agrees well with the duration of the YD in the GRIP ice core according to the time scale of Johnsen et al. [2] (reference time scale in this paper) [10]. Two additional important aspects of the $\mathrm{YD}$, revealed by the $\mathrm{CH}_{4}$-based synchronization of ice core records from GRIP, Byrd (West Antarctica), and Vostok (East Antarctica), are simulated [10]: (i) the apparent thermal antiphasing between the high latitudes of the northern and southern hemispheres; and (ii) the steady and rapid increase in atmospheric $p \mathrm{CO}_{2}$ documented in the Byrd record. By contrast, the model underpredicts the high $\Delta^{14} \mathrm{C}_{\mathrm{atm}}$ at the beginning of the $\mathrm{YD}$ and overpredicts the low $\Delta^{14} \mathrm{C}_{\mathrm{atm}}$ during the second half of the cold interval, as identified in the Cariaco basin record. We examine here whether these misfits can be reduced by implementing a variable $P_{\mathrm{C}-14}$ in the model.

\section{Materials and methods}

\subsection{Model components}

We here give a brief description of our model (for details see [10]). The zonally averaged ocean circulation model represents separately the Atlantic, Indian, and Pacific basins, connected by the Southern Ocean. It is coupled to an energy balance model of the atmosphere and to a thermodynamic sea ice model. The exchange of radiocarbon between the ocean, the atmosphere, and the land biosphere is simulated. We treat ${ }^{14} \mathrm{C}$ as an inorganic tracer in the ocean (for details see appendix $C$ in [25]) since previous freshwater perturbation experiments with our model demonstrated that changes in the ocean biological pumps affect $\Delta^{14} \mathrm{C}_{\mathrm{atm}}$ only slightly (figure 5 in [25]). The atmosphere is assumed to be well mixed with respect to ${ }^{14} \mathrm{C}$. We account for the effect of the increase in atmospheric $p \mathrm{CO}_{2}$ during the last glacial termina- tion on the air-sea exchange of ${ }^{14} \mathrm{CO}_{2}$. The gas transfer velocity for ${ }^{14} \mathrm{CO}_{2}, g$, is scaled according to $g=g^{\circ} \cdot p \mathrm{CO}_{2} / p \mathrm{CO}_{2}^{\circ}[8]$, where $g^{\circ}=9.1 \mathrm{~m} \mathrm{yr}^{-1}$ and $p \mathrm{CO}_{2}{ }^{\circ}=200 \mu \mathrm{atm}$ (cf. Section 2.3) are the values used in the spin-up [10]. We prescribe in all our model experiments a linear increase with time of the atmospheric $p \mathrm{CO}_{2}$ of $11 \mu \mathrm{atm} \mathrm{kyr}{ }^{-1}$, which produces a best fit to ice core $\mathrm{CO}_{2}$ data for the last deglaciation (figure 1d in [10]). Finally the land biosphere is represented by a four-box model. This model accounts only for the dilution effect on $\Delta^{14} \mathrm{C}_{\mathrm{atm}}$ of the gross $\mathrm{CO}_{2}$ fluxes between the land biosphere and the atmosphere (these fluxes are kept constant).

\section{2. $P_{C-14}$ reconstruction}

The normalized production of atmospheric ${ }^{14} \mathrm{C}$ between 17.0 and $9.3 \mathrm{kyr}$ BP (on the GRIP chronology of Johnsen et al. [2]) was calculated from a Greenland ice core record of ${ }^{10} \mathrm{Be}$ flux [14]. The following approach, including two main steps, was used to derive the ${ }^{10} \mathrm{Be}$ fluxes. First, the GISP2 ${ }^{10} \mathrm{Be}$ concentration record (data from Finkel and Nishiizumi; [26]) was translated to the GRIP time scale. The GISP2 chronology was connected to the GRIP chronology by synchronizing large climatic changes during this period; in between, the GISP2 chronology was linearly stretched or compressed. Although the synchronization between 17 and $15 \mathrm{kyr}$ BP (on GRIP time scale) is not well constrained (climate changes were relatively small during this period) possible errors in the synchronization for this period have a negligible impact on the modelled $\Delta^{14} \mathrm{C}_{\mathrm{atm}}$ between 13 and $11 \mathrm{kyr}$ BP. Second, ${ }^{10} \mathrm{Be}$ fluxes were computed from ${ }^{10} \mathrm{Be}$ concentrations and accumulation rates in order to remove the effect of dilution on the ${ }^{10} \mathrm{Be}$ concentration record. The accumulation rates were obtained from the $\delta^{18} \mathrm{O}$ record on the basis of the empirical relationship of Johnsen et al. [27]. The ${ }^{10}$ Be fluxes obtained in this way do not show a significant relationship with the $\delta^{18} \mathrm{O}$ record between 15.0 and $9.3 \mathrm{kyr}$ BP [14]. This suggests that these fluxes are not significantly contaminated by climate-related changes in ${ }^{10} \mathrm{Be}$ transport to, and ${ }^{10} \mathrm{Be}$ deposition at Greenland Summit. An alternative approach 
would have been to use the accumulation rates for the GISP2 ice core, based on layer counting and ice flow modelling [19]. This approach, however, leads to ${ }^{10} \mathrm{Be}$ fluxes that exhibit an apparent relationship with the $\delta^{18} \mathrm{O}$ or accumulation record, so that a third step would be required to remove the climatic component from the ${ }^{10} \mathrm{Be}$ fluxes [28]. Here we opt for the first, simpler approach to derive the accumulation rates and the ${ }^{10} \mathrm{Be}$ fluxes [14]. Some support for the accuracy of this approach comes from the agreement between the ${ }^{36} \mathrm{Cl}$ flux record from GRIP (the fluxes of ${ }^{36} \mathrm{Cl}$, another cosmogenic nuclide, were obtained from the relationship of Johnsen et al. [27]) and a composite record of geomagnetic field intensity from North Atlantic sediments for the period $\sim 43-30$ kyr BP [29].

The $P_{\mathrm{C}-14}$ values were calculated from the ${ }^{10} \mathrm{Be}$ fluxes using the production model of Masarik and Beer [11]. This model uses Monte Carlo techniques to simulate the interaction of cosmic ray particles with the Earth's atmosphere and the subsequent production and transport of secondary particles (like neutrons). Masarik and Beer [11] showed that the calculated neutron fluxes are in reasonable agreement with experimental data based on neutron monitor measurements. The modern global rate of ${ }^{14} \mathrm{C}$ production calculated by this model accords with previous estimates based on the decay rate of the global ${ }^{14} \mathrm{C}$ inventory and on previous theoretical models [11].

Various sources of uncertainty may affect the $P_{\mathrm{C}-14}$ values reconstructed from the Greenland ${ }^{10} \mathrm{Be}$ flux record. The uncertainties in ${ }^{10} \mathrm{Be}$ concentration measurements on GISP2 ice are generally equal to $\sim 3-5 \%$ (1 $\sigma$ measurement error; [26]). The uncertainties in our accumulation rates are difficult to assess, as they depend both on the relationship between accumulation rate and $\delta^{18} \mathrm{O}$ at Greenland Summit and on the possible change of this relationship during the deglaciation [30]. Possible changes in the atmospheric transport of ${ }^{10} \mathrm{Be}$ to Summit are an additional source of uncertainty for the reconstruction of $P_{\mathrm{C}-14}$. Finally the possible uncertainty in the global rates of ${ }^{14} \mathrm{C}$ production calculated by the production model cannot be dismissed. The uncertainty in the rate calculated for modern conditions would be $\sim 10 \%$, owing mainly to uncertainties and statistical errors in the neutron fluxes [11].

The following procedure is adopted in an attempt to account for the uncertainty in the reconstructed $P_{\mathrm{C}-14}$ values. A large number of model experiments $(100)$ with variable $P_{\mathrm{C}-14}$ are generated. Each experiment uses a different $P_{\mathrm{C}-14}$ reconstruction consistent with the original reconstruction of Muscheler et al. [14]. Assuming that the original $P_{\mathrm{C}-14}$ values have a $2 \sigma$ uncertainty of $25 \%$ (see below), we employ an algorithm generating random Gaussian deviates ([31]) to obtain a $P_{\mathrm{C}-14}$ value at each date for which a $P_{\mathrm{C}-14}$ value is available in the original reconstruction. The $P_{\mathrm{C}-14}$ values between two dates are then obtained by linearly interpolating the $P_{\mathrm{C}-14}$ values determined randomly. The $\Delta^{14} \mathrm{C}_{\mathrm{atm}}$ mean anomalies \pm 1 standard deviation for the 100 experiments are then compared to the $\Delta^{14} \mathrm{C}$ records. A more complex procedure would be first to employ, e.g., a cubic smoothing spline in an attempt to remove the noise in the original $P_{\mathrm{C}-14}$ values and then to calculate the deviates around the smoothed version of the original $P_{\mathrm{C}-14}$ reconstruction. We compare in Section 3.2 the model results obtained from the two procedures.

The shaded area in Fig. 2 brackets all the $P_{\mathrm{C}-14}$ values determined from the first procedure. We stress that this area should not be taken as representing the true state of knowledge and confidence regarding the $P_{\mathrm{C}-14}$ record since the $2 \sigma$ uncertainty of $25 \%$ for $P_{\mathrm{C}-14}$ is a subjective estimate (the uncertainties in accumulation rates, for example, cannot be firmly assessed). We will check that our major results are not altered if a larger uncertainty is assumed for $P_{\mathrm{C}-14}$ (Section 4). The original reconstruction documents substantial variations between 17 and $11 \mathrm{kyr}$ BP (pluses connected by linear segments in Fig. 2). The salient features of the reconstruction which are of interest as part of this study are: (i) the local maximum just before the YD onset and another maximum just after the YD onset; (ii) the negative trend during the cold climatic interval; and (iii) the peak after the end of the YD (between $\sim 11.2$ and $11.0 \mathrm{kyr} \mathrm{BP}$ ). 


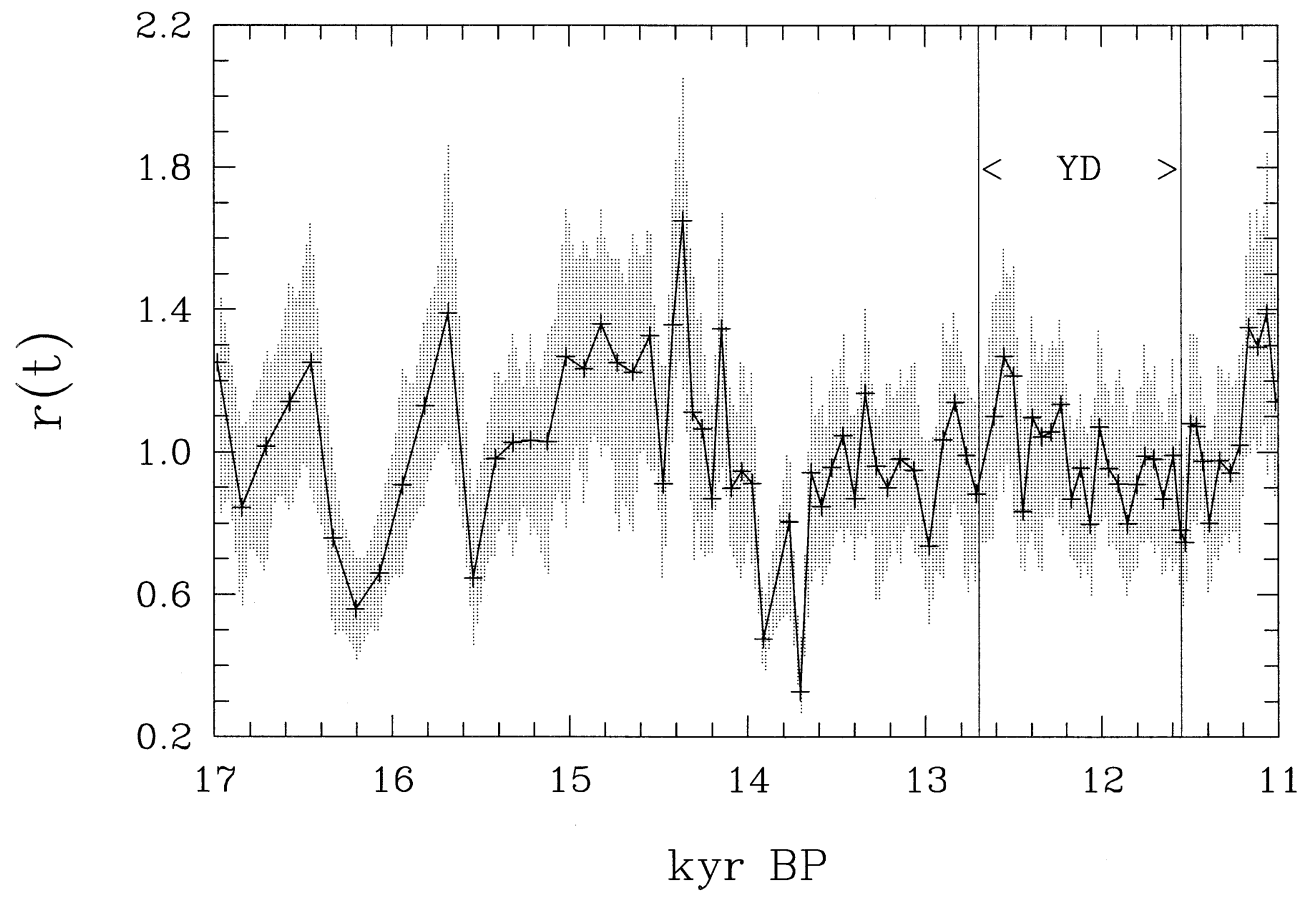

Fig. 2. Production of atmospheric ${ }^{14} \mathrm{C}\left(P_{\mathrm{C}-14}\right)$ between 17 and $11 \mathrm{kyr}$ BP calculated from the Greenland ice core record of ${ }^{10} \mathrm{Be}$ flux. The production values are normalized; they should be multiplied by 1.13 to estimate the values normalized to the modern production rate. The ${ }^{10} \mathrm{Be}$ fluxes were calculated from data of ${ }^{10} \mathrm{Be}$ concentration [26] and from snow accumulation rates estimated according to the method of Johnsen et al. [27]. The original production values of Muscheler et al. [14] are shown by pluses connected by linear segments. The shaded area brackets all the production values determined from the random procedure and used in the model experiments in an attempt to account for the possible inaccuracies in the original $P_{\mathrm{C}-14}$ reconstruction. The two vertical lines denote the onset and termination of the YD as dated in the GRIP ice core [1].

\subsection{Initial conditions}

Several important assumptions must be made in simulations of YD-type events with ocean circulation models (for a short discussion see [10]). A further assumption is necessary here, concerning the calendar time from which a variable $P_{\mathrm{C}-14}$ is implemented in the experiments $\left(t_{\mathrm{P}-\mathrm{C} 14}\right.$ hereafter). Since ${ }^{14} \mathrm{C}$ cycling between the various carbon reservoirs (atmosphere, ocean, and land biosphere) acts as a low pass filter with respect to the production variations, the simulated $\Delta^{14} \mathrm{C}_{\text {atm }}$ anomalies depend on the $P_{\mathrm{C}-14}$ changes prescribed before the YD and thus on $t_{\mathrm{P}-\mathrm{C} 14}$. Here we start to implement a variable $P_{\mathrm{C}-14}$ at $t_{\mathrm{P}-\mathrm{Cl} 4}=16982 \mathrm{yr}$ BP (about $4.3 \mathrm{kyr}$ before the YD onset). We note that significant climate changes probably occurred between this date and the onset of the YD (e.g. [32]), which are not taken into account in our model experiments. These changes might have preconditioned the $\Delta^{14} \mathrm{C}_{\mathrm{atm}}$ variations during the YD and it is therefore assumed that this possible preconditioning was negligible.

The model is spun-up with a prescribed $\Delta \Delta^{14} \mathrm{C}_{\mathrm{atm}}=300 \%$ and $p \mathrm{CO}_{2}{ }^{\circ}=200 \mu \mathrm{atm}$, consistent with $\Delta^{14} \mathrm{C}_{\mathrm{atm}}$ estimated from ${ }^{14} \mathrm{C}$ datings of Tahiti corals (figure 2 in [21]) and with $\mathrm{CO}_{2}$ data from an Antarctic ice core at $\sim 17 \mathrm{kyr}$ BP (figure $1 \mathrm{~d}$ in [10]). We then use the following equation to implement a variable $P_{\mathrm{C}-14}$ :

$P_{\mathrm{C}-14}(t)=P_{\mathrm{C}-14}^{d} \times r(t) / r\left(t_{\mathrm{P}-\mathrm{C} 14}\right)$

$P_{\mathrm{C}-14}^{d}$ is the production rate diagnosed from the model spin-up (for details see [8]), which would correspond to the production at calendar time $t_{\mathrm{P}-\mathrm{C} 14} \cdot r(t)$ and $r\left(t_{\mathrm{P}-\mathrm{C} 14}\right)$ are the normalized production rates at calendar times $t$ and $t_{\mathrm{P}-\mathrm{C} 14}$ 
$\left(t<t_{\mathrm{P}-\mathrm{C} 14}\right)$. These rates differ from one experiment to the other given the random procedure described above. Other details concerning the model spin-up are given in Marchal et al. [10].

\section{Model results}

\subsection{Variable $T H C$ and constant $P_{C-14}$}

Previous simulations of a YD-type event conducted with ocean circulation models assumed a constant $P_{\mathrm{C}-14}$. These simulations predict a $\Delta^{14} \mathrm{C}_{\mathrm{atm}}$ rise of $10-40 \%$ during the cold phase and a $\Delta^{14} \mathrm{C}_{\mathrm{atm}}$ decline only at the end of this phase $[8,10,33]$. Accordingly, these simulations underestimate the high $\Delta^{14} C_{a t m}$ levels during the first half of the YD and overestimate the low $\Delta^{14} \mathrm{C}_{\mathrm{atm}}$ levels during the second half of the YD and after the YD termination, as documented in the Cariaco basin record. The comparison of the dashed line (produced with our model with constant $P_{\mathrm{C}-14}$ ) and filled circles (Cariaco basin data) on Fig. 1a illustrates this chronic model misfit. It was suggested that the early $\Delta{ }^{14} \mathrm{C}_{\mathrm{atm}}$ drawdown observed during the YD would reflect an enhancement in the formation of North Atlantic Intermediate Water [17] or Southern Ocean water [34], both features which would not be predicted in simulations of a YD-type event with ocean circulation models.

The initial $\Delta{ }^{14} \mathrm{C}_{\mathrm{atm}}$ increase simulated by our model would seem more consistent with the Polish lake $\Delta^{14} \mathrm{C}$ record (compare dashed line with open circles in Fig. 1a). It is clear, however, that the scatter in this record does not permit a firm evaluation of the modelled increase. On the other hand, the model overpredicts most of the lakebased $\Delta^{14} \mathrm{C}_{\mathrm{atm}}$ values during the second half of the YD and the early Preboreal. Thus, the model scenario with variable THC and constant $P_{\mathrm{C}-14}$ is not consistent with the $\Delta^{14} \mathrm{C}_{\mathrm{atm}}$ evolution during and after the YD, as constrained from the Cariaco basin and Polish lake records.

\subsection{Constant $T H C$ and variable $P_{C-14}$}

We consider a first series of 100 experiments with constant THC and variable $P_{\mathrm{C}-14}$, to examine the hypothesis that changes in radiocarbon production alone have dominated $\Delta^{14} \mathrm{C}_{\mathrm{atm}}$ throughout the YD. The difference between the mean $\Delta^{14} \mathrm{C}_{\mathrm{atm}}$ anomalies simulated with $P_{\mathrm{C}-14}$ values obtained from the first procedure and the smoothing procedure (Section 2.2; with a smoothing parameter of 10 ) averages only $4 \%$ (not shown). The choice of the procedure has therefore a poor impact on the simulated $\Delta^{14} \mathrm{C}_{\mathrm{atm}}$ levels. We consider below only the $\Delta^{14} \mathrm{C}_{\mathrm{atm}}$ anomalies produced from the first procedure.

The mean $\Delta^{14} \mathrm{C}_{\mathrm{atm}}$ anomalies are now qualitatively consistent with the Cariaco basin record, as maximum $\Delta^{14} \mathrm{C}_{\mathrm{atm}}$ levels are predicted during the first half of the cold phase and followed by a gradual decline (compare solid line with filled circles in Fig. 1a). Including a variable $P_{\mathrm{C}-14}$ thus improves the prediction of $\Delta{ }^{14} \mathrm{C}_{\mathrm{atm}}$, compared to our previous simulation with constant $P_{\mathrm{C}-14}$ (dashed line in Fig. 1a; [10]). This improvement stems from the local $P_{\mathrm{C}-14}$ maxima close to the onset of the YD and from the decreasing $P_{\mathrm{C}-14}$ during the cold climatic interval (Fig. 2). However, compared to the Cariaco basin record, the model underpredicts markedly the $\Delta^{14} C_{a t m}$ anomalies during the YD and overpredicts the anomalies after the end of the event (Fig. 1a). The simulated $\Delta^{14} \mathrm{C}_{\text {atm }}$ anomalies seem, on average, more consistent with the Polish lake data, but the scatter in this data set appears again too large to really constrain the performance of the model.

\subsection{Variable $T H C$ and variable $P_{C-14}$}

We now consider the results from a second series of 100 experiments, where both the deep ocean ventilation and the production of atmospheric ${ }^{14} \mathrm{C}$ are allowed to vary. In all the experiments the formation of deep waters in the northern North Atlantic drops from $24 \mathrm{~Sv}\left(1 \mathrm{~Sv}=10^{6} \mathrm{~m}^{3} \mathrm{~s}^{-1}\right)$ to $\sim 2 \mathrm{~Sv}$ during the model cold phase and resumes to $\sim 24 \mathrm{~Sv}$ at the end of this phase [10]. The model reproduces more realistically the high $\Delta^{14} C_{a t m}$ anomalies throughout the YD identified in the Cariaco basin record (compare solid line with filled circles in Fig. 1b), compared to the scenario with constant THC (Fig. 1a). That is, 
both the $\Delta^{14} \mathrm{C}_{\mathrm{atm}}$ increase at the YD onset and the $\Delta^{14} \mathrm{C}_{\mathrm{atm}}$ drawdown during the second half of the cold event are more accurately replicated. By contrast, the fit to the $\Delta^{14} \mathrm{C}_{\mathrm{atm}}$ anomalies observed during the early Preboreal is worse. The scatter in the lake data set seems again too large to identify which of the two previous model scenarios, i.e. constant versus variable THC, produces the most realistic results (compare Fig. 1a with Fig. 1b).

\subsection{Adding a long-term $P_{C-14}$ decline}

In all scenarios considered so far the model overestimates generally the $\Delta^{14} \mathrm{C}_{\mathrm{atm}}$ anomalies from the Cariaco basin record between $\sim 11.5$ and $11.0 \mathrm{kyr}$ BP (Fig. 1a,b). The high $\Delta^{14} \mathrm{C}_{\mathrm{atm}}$ anomalies simulated by the model are clearly due to the pronounced $P_{\mathrm{C}-14}$ increase during this period (Fig. 2). The few published $\Delta^{14} \mathrm{C}$ data from the Cariaco basin for the YD/Preboreal transition and early Preboreal are concordant with the tree-ring $\Delta{ }^{14} \mathrm{C}$ record [17]. Thus these data are very probably accurate and a further investigation of the model misfit is warranted.

Interestingly, the $P_{\mathrm{C}-14}$ reconstruction between 17 and 11 kyr BP does not contain a long-term decline (Fig. 2), as detected from $\sim 40 \mathrm{kyr}$ BP onwards in globally stacked paleomagnetic records and ${ }^{10} \mathrm{Be}$ flux records from marine sediments [35,36]. A long-term $P_{\mathrm{C}-14}$ decline from the low in Earth's dipole moment at $\sim 40 \mathrm{kyr}$ (possibly associated with the Laschamp excursion; [37]) is presumably responsible for the overall $\Delta{ }^{14} \mathrm{C}_{\mathrm{atm}}$ decrease since then documented by ${ }^{14} \mathrm{C}$ datings of fossil corals [21]. The most recent composite record of ${ }^{10} \mathrm{Be}$ flux to marine sediments documents a trend in global ${ }^{10} \mathrm{Be}$ production from $\sim 30$ to $10 \mathrm{kyr} \mathrm{BP}$ equivalent to $\sim-0.7$ relative units $(30 \mathrm{kyr})^{-1}$ (figure 4 in [36]; figure 3 in [38]). The uncertainty of this trend is probably less than a factor of two, based on the standard error of the mean global ${ }^{10} \mathrm{Be}$ production during this period [36,38]. We add this trend to the original $P_{\mathrm{C}-14}$ reconstruction of Muscheler et al. [14] and determine randomly new $P_{\mathrm{C}-14}$ values (Section 2.2). A third series of 100 experiments including this trend are then conducted to exam- ine whether this would reduce the model misfit to the $\Delta^{14} \mathrm{C}$ of the early Preboreal observed in the Cariaco basin record. The underlying assumption in this exercise is that the trend in the global marine ${ }^{10} \mathrm{Be}$ stack reflects an increase in geomagnetic field intensity which is not recorded in the Greenland ${ }^{10} \mathrm{Be}$ flux record between 17 and $11 \mathrm{kyr} \mathrm{BP}$ (see Section 4).

Including the trend reduces significantly the simulated $\Delta^{14} \mathrm{C}_{\mathrm{atm}}$ levels on the time scale of 2 kyr (between 13 and 11 kyr BP). Compared to the Cariaco basin record, this brings the model a bit farther from the high $\Delta^{14} \mathrm{C}$ during the first half of the YD, but much closer to the $\Delta^{14} \mathrm{C}$ data for the early Preboreal (compare solid line with filled circles in Fig. 1c). This result suggests that the lack of an overall decline in the Greenland ${ }^{10} \mathrm{Be}$ flux record between $\sim 17$ and $11 \mathrm{kyr} \mathrm{BP}$ could be responsible, at least partly, for the overpredicted $\Delta^{14} \mathrm{C}_{\mathrm{atm}}$ levels during this period.

\section{Discussion and outlook}

In this study a large number of experiments based on a zonally averaged ocean circulation model are examined to explore the influence on $\Delta{ }^{14} \mathrm{C}_{\mathrm{atm}}$ of $P_{\mathrm{C}-14}$ changes during the YD inferred from the Greenland ${ }^{10} \mathrm{Be}$ record. We find that the high $\Delta^{14} \mathrm{C}_{\mathrm{atm}}$ levels during the cold event documented in the Cariaco basin record are generally best predicted in the experiments characterized both by $P_{\mathrm{C}-14}$ changes and a drop in the Atlantic THC. By contrast, the early drawdown in atmospheric ${ }^{14} \mathrm{C}$ activity which initiated during the first half of the YD can be explained only by $P_{\mathrm{C}-14}$ changes. This suggests that the drawdown would not be the signature of an increasing formation of North Atlantic Intermediate Water [17], Southern Ocean water [34], or any other deep ocean water during the cold climatic episode.

Furthermore, the scatter in the Polish lake $\Delta^{14} \mathrm{C}$ data makes it delicate to identify which of our model scenarios (constant THC versus variable THC) provides the most realistic prediction of the $\Delta^{14} \mathrm{C}_{\mathrm{atm}}$ changes both at the onset and during the YD. We note that the $\Delta{ }^{14} C_{a t m}$ rises predicted in simulations of a YD-type event with a three- 
dimensional (3-d) ocean circulation model (10$20 \%$ with constant $P_{\mathrm{C}-14}$; [33]) are smaller than the rises predicted by our zonally averaged model $\left(30-40 \%\right.$ with constant $\left.P_{\mathrm{C}-14}\right)$. Accordingly, the verification of 3 -d model simulations from $\Delta^{14} \mathrm{C}_{\mathrm{atm}}$ records characterized by a scatter comparable to that of the Polish lake data set would be even more difficult.

To test the robustness of our results we consider the mean $\Delta^{14} \mathrm{C}_{\mathrm{atm}}$ from three series of $100 \mathrm{sim}$ ulations assuming a $2 \sigma$ uncertainty of $50 \%$ for $P_{\mathrm{C}-14}$. The difference between the mean $\Delta^{14} \mathrm{C}_{\mathrm{atm}}$ simulated with a $2 \sigma$ uncertainty of $25 \%$ and $50 \%$ for $P_{\mathrm{C}-14}$ averages $3 \%$ for the scenario with constant THC and variable $P_{\mathrm{C}-14}$, and $4 \%$ for the scenario with variable THC and variable $P_{\mathrm{C}-14}$. These small differences indicate that our major results are robust against the uncertainties assumed for $P_{\mathrm{C}-14}$. On the other hand, we note that even with a $2 \sigma$ uncertainty of $25 \%$ for $P_{\mathrm{C}-14}$ the $1 \sigma$ bands for $\Delta{ }^{14} \mathrm{C}_{\mathrm{atm}}$ in the different scenarios overlap (Fig. 1a,b). This points clearly to the necessity to reduce the uncertainty in the reconstructed $P_{\mathrm{C}-14}$ for a better assessment of the effects of $P_{\mathrm{C}-14}$ changes and ocean ventilation changes on the $\Delta^{14} \mathrm{C}_{\mathrm{atm}}$ record.

Two major features in the Cariaco basin $\Delta^{14} \mathrm{C}$ record between 13 and $11 \mathrm{kyr} \mathrm{BP}$ are not replicated in our simulation of a YD-type event when supplied with the variable $P_{\mathrm{C}-14}$ based on the Greenland ${ }^{10} \mathrm{Be}$ record. These misfits must result from the deficiencies of our model, the possible inaccuracies in the $P_{\mathrm{C}-14}$ reconstruction, and/or the possible inaccuracies in the $\Delta^{14} \mathrm{C}$ record. First our model generally overestimates the Cariaco ba$\sin \Delta^{14} \mathrm{C}$ levels between $\sim 11.5$ and $11.0 \mathrm{kyr} \mathrm{BP}$ (Fig. 1a,b). Second the rapid $\Delta^{14} C_{a t m}$ rise at the Allerød/YD transition is underpredicted (Fig. 1ac). We discuss these two misfits below.

\section{1. $\Delta^{14} C_{\text {atm }}$ during Preboreal}

The period between 11.5 and $11.0 \mathrm{kyr}$ BP encompasses the Preboreal Oscillation [16]. It was suggested that the $\Delta^{14} \mathrm{C}_{\mathrm{atm}}$ increase during the Preboreal Oscillation documented in the dendrorecord (cf. the three youngest $\Delta^{14} \mathrm{C}$ values of the Cariaco basin record; filled circles in Fig. 1) was created by a freshwater-induced reduction in deep ocean ventilation [16]. Were such an additional reduction present in our experiments, even larger $\Delta^{14} \mathrm{C}_{\mathrm{atm}}$ anomalies would be predicted and the misfit to the $\Delta^{14} \mathrm{C}_{\mathrm{atm}}$ reconstruction between 11.5 and $11.0 \mathrm{kyr}$ BP would be worse.

We found, on the other hand, that adding a negative long-term trend to the $P_{\mathrm{C}-14}$ data, constrained from a composite marine record of ${ }^{10} \mathrm{Be}$ deposition rate, reduces the model misfit to the Cariaco basin $\Delta^{14} \mathrm{C}$ levels for the early Preboreal (Fig. 1c). This addition was justified by the fact that both paleomagnetic and ${ }^{10} \mathrm{Be}$ records from deep sea sediments document such a trend, which is absent in the $P_{\mathrm{C}-14}$ reconstruction based on the Greenland ${ }^{10} \mathrm{Be}$ record (at least for the period $17-$ $11 \mathrm{kyr}$ BP; Fig. 2). It is clear, however, that the better model fit obtained with a $P_{\mathrm{C}-14}$ trend cannot be taken, per se, as a support for its existence during this period. There would be various possible explanations for the apparent discordancy between the Greenland record and the global marine stacks. For instance, the geomagnetic modulation of cosmonuclide production should be comparatively small at polar latitudes (where the horizontal component of the geomagnetic field is reduced), which would explain the lack of the trend in the Greenland record. However, there is evidence that a large fraction of the precipitation at high elevation areas of the Greenland ice sheet originates from lower latitudes, and this under both modern and glacial climate conditions $[39,40]$. Furthermore, a good agreement was found for the period 96-25 kyr BP between the GRIP record of ${ }^{36} \mathrm{Cl}$ and a reconstruction of the Earth dipole moment based on sediment cores raised from the Somali Basin [41]. This is a strong indication that the deposition of cosmonuclides at the Greenland Summit should be sensitive to changes in the global geomagnetic field intensity. On the other hand, the high latitudes are underrepresented in composite marine records [35,36], which could thus overestimate these fluctuations which are most pronounced close to the magnetic equator. The bias towards lower latitudes in global marine stacks, however, should not be too problematic for ${ }^{10} \mathrm{Be}$, as this element is removed from seawater on a time scale comparable to that 
of large-scale oceanic mixing; the geography of ${ }^{10} \mathrm{Be}$ deposition at the sea floor would be much more uniform than the geography of ${ }^{10} \mathrm{Be}$ deposition at the sea surface [42]. Another problem would be a possible contamination of marine sediment records of natural remanent magnetizations and ${ }^{10} \mathrm{Be}$ flux by climatic effects [43].

\subsection{Rapid $\Delta^{14} C_{\text {atm }}$ rise at Allerød/YD boundary}

The second feature in the Cariaco basin $\Delta^{14} \mathrm{C}$ record not replicated by our model is the rapidity of the $\Delta^{14} C_{a t m}$ increase at the onset of the YD. Almost all available high-resolution ${ }^{14} \mathrm{C}$ data for the Allerød/YD boundary show a rapid age decline $\left(\Delta^{14} \mathrm{C}\right.$ increase) from $\sim 10.8-11.0{ }^{14} \mathrm{C}$ kyr BP to $\sim 10.6{ }^{14} \mathrm{C} \mathrm{kyr} \mathrm{BP}$ (see [16] and references therein). This decline is, to our opinion, very important and it would be very valuable to be able to model it.

Unlike for the Preboreal, tree-ring ${ }^{14} \mathrm{C}$ data are not available to constrain the accuracy of the Cariaco basin data for the YD onset. The ${ }^{14} \mathrm{C}$ ages from this basin (obtained on fossil planktonic foraminifera) need to be corrected for the reservoir effect. Here we have followed Hughen et al. [17], by using an average measured reservoir age of 420 yr to correct the Cariaco basin ${ }^{14} \mathrm{C}$ ages. The reservoir age of North Atlantic waters during the YD, however, could have been different from the pre-industrial one. Radiocarbon datings of fossil planktonic foraminifera from North Atlantic sediments and of terrestrial plant remains (from Iceland and Norwegian lakes), mixed with the same volcanic tephra (Vedde Ash Bed), indicate that the air-sea ${ }^{14} \mathrm{C}$ disequilibrium during the YD amounted to about 700-800 yr compared to a pre-industrial value of 400-500 yr [44]. Freshwater perturbation experiments with our zonally averaged model show changes of several hundred years for the reservoir age of North Atlantic waters $[8,45]$. Although it is delicate to extrapolate these site-specific observations and coarse-resolution model results to the Cariaco basin surface waters, they at least point to the possibility that these waters experienced significant changes in reservoir age at the Allerød/YD boundary. It is clearly desirable to better constrain these potential changes (perhaps through ${ }^{14} \mathrm{C}$ datings on individual organic compounds of marine and terrestrial origin in the same core samples; [46]) and to extend the dendro- $\Delta{ }^{14} \mathrm{C}$ record all across the $\mathrm{YD}$ [47]. All in all, if the rapid $\Delta^{14} \mathrm{C}$ increase at the onset of the YD observed in the Cariaco basin record is a faithful reflection of a $\Delta^{14} \mathrm{C}$ change in the atmosphere at that time, the previous concern to explain the early $\Delta{ }^{14} \mathrm{C}_{\mathrm{atm}}$ drawdown during the YD $[10,17,18,34]$ should be substituted by a new concern to explain this increase.

\subsection{Other future directions}

Two additional areas of research could lead to a better understanding of the probable changes in deep ocean ventilation during the YD. First the possible inaccuracies in global ${ }^{14} \mathrm{C}$ production estimated from cosmonuclide records from polar ice cores warrant further analysis. For instance the ${ }^{10} \mathrm{Be}$ flux at a given location is potentially contaminated by ${ }^{10} \mathrm{Be}$ recycled by dust particles [13]. Baumgartner et al. [48] estimated that the contribution of dust borne ${ }^{10} \mathrm{Be}$ to total ${ }^{10} \mathrm{Be}$ flux in the GRIP core is mostly smaller than $5 \%$ for Holocene ice, but averages $\sim 20 \%$ for Pleistocene ice and $\sim 40 \%$ at the very bottom of the core. The increase with depth of the fraction of dust borne ${ }^{10} \mathrm{Be}$, however, could indicate that the dust borne ${ }^{10} \mathrm{Be}$ is not recycled ${ }^{10} \mathrm{Be}$, but freshly produced ${ }^{10} \mathrm{Be}$ which attached progressively to dust in situ [49]. Another deficiency of our approach to derive the ${ }^{10} \mathrm{Be}$ fluxes comes from possible changes in the relationship between accumulation rate and $\delta^{18} \mathrm{O}$ during the deglaciation at Greenland Summit [30]. Also, ${ }^{10} \mathrm{Be}$ transport in the atmosphere must be better understood to correct for potential changes in ${ }^{10} \mathrm{Be}$ transport and to reduce errors in the reconstructed $P_{\mathrm{C}-14}$.

Second, a major limitation of our study is the use of a zonally averaged model, which may produce a poor estimate of the effect of THC and/or $P_{\mathrm{C}-14}$ changes on the atmospheric ${ }^{14} \mathrm{C}$ activity. For example, the effect of brine rejection during sea ice formation around Antarctica is crudely represented in this model which does not include a seasonal cycle [8]. This representation may or may not be accurate, resulting in greater or lesser 
increases in the rate of formation of deep waters along the Antarctic perimeter following a shutdown in the formation of deep waters in the northern North Atlantic. Similarly, our model does not account for changes in wind velocity during the $\mathrm{YD}$, and accompanying changes in air-sea exchange rate of ${ }^{14} \mathrm{CO}_{2}$. Using the same model, Stocker and Wright [8] mentioned the potential influence on $\Delta^{14} \mathrm{C}_{\mathrm{atm}}$ of artificially but realistically extending sea ice coverage in the North Atlantic in a simulation of a YD-type event. The efforts to predict $\Delta^{14} C_{a t m}$ changes during such events with more complete ocean models should thus be pursued. For example, there are presently only two simulations of a YD-type event, based on a 3-d ocean model and which include a description of ${ }^{14} \mathrm{C}$ cycling in the ocean and the atmosphere [33]. Provided that it is possible to conduct a large number of sensitivity tests with $3-d$ ocean models (as done here with a zonally averaged model), the comparison of $\Delta^{14} \mathrm{C}_{\mathrm{atm}}$ anomalies predicted by such models with the $\Delta^{14} \mathrm{C}_{\mathrm{atm}}$ reconstruction should provide better constraints on the probable changes in deep ocean ventilation at the onset, during, and at the termination of the YD cold spell.

\section{Acknowledgements}

We thank J. Beer, S. Björck, M. Frank, and one anonymous reviewer for useful comments on the manuscript. We are grateful to J. Schwander for details about differences between GRIP chronologies and about estimates of past accumulation rates at Greenland Summit. This study was made possible by the Swiss National Science Foundation and the European projects 'Mileclim' and 'Holocene Ocean Instability'.[EB]

\section{References}

[1] S.J. Johnsen, H.B. Clausen, W. Dansgaard, K. Fuhrer, N. Gundestrup, C.U. Hammer, P. Iversen, J. Jouzel, B. Stauffer, J.P. Steffensen, Irregular interstadials recorded in a new Greenland ice core, Nature 359 (1992) 311-313.

[2] S.J. Johnsen, H.B. Clausen, W. Dansgaard, N.S. Gundestrup, C.U. Hammer, K.K. Andersen, C.S. Hvidberg,
D. Dahl-Jensen, J.P. Steffensen, H. Shoji, A.E. Sveinbjørnsdóttir, J. White, J. Jouzel, D. Fisher, The $\delta^{18} \mathrm{O}$ record along the Greenland Ice Core Project deep ice core and the problem of possible Eemian climatic instability, J. Geophys. Res. 102 (1997) 26397-26410.

[3] S. Manabe, R.J. Stouffer, Coupled ocean-atmosphere model response to freshwater input: Comparison to Younger Dryas event, Paleoceanography 12 (1997) 321336.

[4] A. Schiller, U. Mikolajewicz, R. Voss, The stability of the North Atlantic thermohaline circulation in a coupled ocean-atmosphere general circulation model, Clim. Dyn. 13 (1997) 325-347.

[5] T.F. Stocker, A. Schmittner, Influence of $\mathrm{CO}_{2}$ emission rates on the stability of the thermohaline circulation, $\mathrm{Na}$ ture 388 (1997) 862-865.

[6] W.S. Broecker, D. Peteet, D. Rind, Does the ocean-atmosphere system have more than one stable mode of operation?, Nature 315 (1985) 21-25.

[7] D.G. Wright, T.F. Stocker, Younger Dryas experiments, in: W.R. Peltier (Ed.), Ice in the Climate System, NATO ASI Ser., Ser. I, 12, 1993, pp. 395-416.

[8] T.F. Stocker, D.G. Wright, Rapid changes in ocean circulation and atmospheric radiocarbon, Paleoceanography 11 (1996) 773-796.

[9] A.F. Fanning, A.J. Weaver, Temporal-geographical meltwater influences on the North Atlantic conveyor: Implications for the Younger Dryas, Paleoceanography 12 (1997) 307-320.

[10] O. Marchal, T.F. Stocker, F. Joos, A. Indermühle, T. Blunier, T. Tschumi, Modelling the concentration of atmospheric $\mathrm{CO}_{2}$ during the Younger Dryas climate event, Clim. Dyn. 15 (1999) 341-354.

[11] J. Masarik, J. Beer, Simulation of particle fluxes and cosmogenic nuclide production in the Earth's atmosphere, J. Geophys. Res. 104 (1999) 12099-12111.

[12] W.S. Broecker, T.-H. Peng, Tracers in the Sea, Eldigio Press, Lamont-Doherty Geological Observatory, Palisades, NY, 1982.

[13] L.R. McHargue, P.E. Damon, The global beryllium-10 cycle, Rev. Geophys. 29 (1991) 141-158.

[14] R. Muscheler, J. Beer, G. Wagner, R.C. Finkel, Changes in deep-water formation during the Younger Dryas event inferred from ${ }^{10} \mathrm{Be}$ and ${ }^{14} \mathrm{C}$ records, Nature 408 (2000) $567-570$.

[15] T. Goslar, M. Arnold, E. Bard, T. Kuc, M.F. Pazdur, M. Ralska-Jasiewiczowa, K. Rozallski, N. Tisnerat, A. Walanus, B. Wicik, K. Wieckowski, High concentration of atmospheric ${ }^{14} \mathrm{C}$ during the Younger Dryas cold episode, Nature 377 (1995) 414-417.

[16] S. Björck, B. Kromer, S. Johnsen, O. Bennike, D. Hammarlund, G. Lemdahl, G. Possnert, T.L. Rasmussen, B. Wohlfarth, C.U. Hammer, M. Spurk, Synchronized terrestrial-atmospheric deglacial records around the North Atlantic, Science 274 (1996) 1155-1160.

[17] K.A. Hughen, J.T. Overpeck, S.J. Lehman, M. Kashgarian, J. Southon, L.C. Peterson, R. Alley, D.M. Sigman, 
Deglacial changes in ocean circulation from an extended radiocarbon calibration, Nature 391 (1998) 65-68.

[18] T. Goslar, B. Wohlfarth, S. Björck, G. Possnert, J. Björck, Variations of atmospheric ${ }^{14} \mathrm{C}$ over the AllerødYounger Dryas transition, Clim. Dyn. 15 (1999) 29-42.

[19] R.B. Alley, D.A. Meese, C.A. Shuman, A.J. Gow, K.C. Taylor, P.M. Grootes, J.W.C. White, M. Ram, E.D. Waddington, P.A. Mayewski, G.A. Zielinski, Abrupt increase in Greenland snow accumulation at the end of the Younger Dryas event, Nature 362 (1993) 527-529.

[20] R.L. Edwards, W.J. Beck, G.S. Burr, D.J. Donahue, J.M.A. Chappell, A.L. Bloom, E.R.M. Druffel, F.W. Taylor, A large drop in atmospheric ${ }^{14} \mathrm{C} /{ }^{12} \mathrm{C}$ and reduced melting in the Younger Dryas, documented with ${ }^{230} \mathrm{Th}$ ages of corals, Science 260 (1993) 962-968.

[21] E. Bard, Geochemical and geophysical implications of the radiocarbon calibration, Geochim. Cosmochim. Acta 62 (1998) 2025-2038.

[22] T. Goslar, M. Arnold, N. Tisnerat-Laborde, J. Czernik, K. Wieckowski, Variations of Younger Dryas atmospheric radiocarbon explicable without ocean circulation changes, Nature 403 (2000) 877-880.

[23] E. Tric, J.-P. Valet, P. Tucholka, M. Paterne, L. Labeyrie, F. Guichard, L. Tauxe, M. Fontugne, Paleointensity of the geomagnetic field during the last 80000 years, J. Geophys. Res. 97 (1992) 9337-9351.

[24] D. Lal, Theoretically expected variations in the terrestrial cosmic-ray production rates of isotopes, in: Solar-Terrestrial Relationships and the Earth Environment in the Last Millennia, Soc. Italiana di Fisica, Bologna, 1988, pp. 216233.

[25] O. Marchal, T.F. Stocker, F. Joos, Physical and biogeochemical responses to freshwater-induced thermohaline variability in a zonally averaged ocean model, in: $\mathrm{R}$. Webb, P.U. Clark, L.D. Keigwin (Eds.), Mechanisms of Global Climate Change at Millennial Time Scales, Vol. 112 of Geophysical Monograph, Am. Geophys. Union, 1999, pp. 263-284.

[26] R.C. Finkel, K. Nishiizumi, Beryllium-10 concentrations in the Greenland Ice Sheet Project 2 ice core from 3-40 ka, J. Geophys. Res. 102 (1997) 26699-26706.

[27] S.J. Johnsen, D. Dahl-Jensen, W. Dansgaard, N. Gundestrup, Greenland palaeotemperatures derived from GRIP bore hole temperature and ice core isotope profiles, Tellus B47 (1995) 624-629.

[28] R.B. Alley, R.C. Finkel, K. Nishiizumi, A. Anandakrishnan, A. Shuman, G.R. Mershon, G.A. Zielinski, P.A. Mayewski, Changes in continental and sea-salt atmospheric loadings in central Greenland during the most recent deglaciation: Model-based estimates, J. Glaciol. 41 (1995) 503-514.

[29] G. Wagner, J. Beer, C. Laj, C. Kissel, J. Masarik, R. Muscheler, H.-A. Synal, Chlorine-36 evidence for the Mono Lake event in the Summit GRIP ice core, Earth Planet. Sci. Lett. 181 (2000) 1-6.

[30] W.R. Kapsner, R.B. Alley, C.A. Shuman, S. Anandakrishnan, P.M. Grootes, Dominant influence of atmos- pheric circulation on snow accumulation in Greenland over the last 18000 years, Nature 373 (1995) 52-54.

[31] W.H. Press, S.A. Teukolsky, W.T. Vetterling, B.P. Flannery, Numerical Recipes (in Fortran) - The Art of Scientific Computing, 2nd edn., Cambridge University Press, 1992, 963 pp.

[32] J.P. Severinghaus, E.J. Brook, Abrupt climate change at the end of the last glacial period inferred from trapped air in polar ice, Science 286 (1999) 930-934.

[33] U. Mikolajewicz, A meltwater-induced collapse of the 'conveyor belt' thermohaline circulation and its influence on the distribution of $\Delta^{14} \mathrm{C}$ and $\delta^{18} \mathrm{O}$ in the oceans, Technical Report 189, Max-Planck-Inst. für Meteorologie, Hamburg, 1996, pp. 1-25.

[34] W.S. Broecker, Paleocean circulation during the last deglaciation: A bipolar seesaw, Paleoceanography 13 (1998) 119-121.

[35] Y. Guyodo, J.-P. Valet, Relative variations in geomagnetic intensity from sedimentary records: The past 200000 years, Earth Planet. Sci. Lett. 143 (1996) 23-36.

[36] M. Frank, B. Schwarz, S. Baumann, P.W. Kubik, M. Suter, A. Mangini, A $200 \mathrm{kyr}$ record of cosmogenic radionuclide production rate and geomagnetic field intensity from ${ }^{10} \mathrm{Be}$ in globally stacked deep-sea sediments, Earth Planet. Sci. Lett. 149 (1997) 121-129.

[37] S. Levi, H. Audunsson, R.A. Duncan, L. Kristjansson, P.-Y. Gillot, S.P. Jakobsson, Late Pleistocene geomagnetic excursion in Iceland lavas: Confirmation of the Laschamp excursion, Earth Planet. Sci. Lett. 96 (1990) 443-457.

[38] M. Frank, Comparison of cosmogenic radionuclide production and geomagnetic field intensity over the last 200000 years, Phil. Trans. R. Soc. Lond. 358 (2000) 1089-1107.

[39] S.J. Johnsen, W. Dansgaard, J.W.C. White, The origin of Arctic precipitation under present and glacial conditions, Tellus B41 (1989) 452-468.

[40] C.D. Charles, D. Rind, J. Jouzel, R.D. Koster, R.G. Fairbanks, Glacial-interglacial changes in moisture sources for Greenland: Influences on the ice core record of climate, Science 263 (1994) 508-511.

[41] S. Baumgartner, J. Beer, J. Masarik, G. Wagner, L. Meynadier, H.-A. Synal, Geomagnetic modulation of the ${ }^{36} \mathrm{Cl}$ flux in the GRIP ice core, Greenland, Science 279 (1998) $1330-1332$.

[42] F. von Blanckenburg, H. Igel, Lateral mixing and advection of reactive isotope tracers in ocean basins: Observations and mechanisms, Earth Planet. Sci. Lett. 169 (1999) $113-128$.

[43] Y.S. Kok, Climatic influence in NRM and ${ }^{10}$ Be-derived geomagnetic paleointensity data, Earth Planet. Sci. Lett. 166 (1999) 105-119.

[44] E. Bard, M. Arnold, J. Mangerud, M. Paterne, L. Labeyrie, J. Duprat, M.-A. Melieres, E. Sønstegaard, J.-C. Duplessy, The North Atlantic atmosphere-sea surface ${ }^{14} \mathrm{C}$ gradient during the Younger Dryas climatic event, Earth Planet. Sci. Lett. 126 (1994) 275-287.

[45] T.F. Stocker, D.G. Wright, The effect of a succession of 
ocean ventilation changes on ${ }^{14} \mathrm{C}$, Radiocarbon 40 (1998) 359-366.

[46] T.I. Eglinton, B.C. Benitez-Nelson, A. Pearson, A.P. McNichol, J.E. Bauer, E.R.M. Druffel, Variability in radiocarbon ages of individual organic compounds from marine sediments, Science 277 (1997) 796-799.

[47] B. Kromer, M. Spurk, Revision and tentative extension of the tree-ring based ${ }^{14} \mathrm{C}$ calibration $9200-11855$ cal. BP, Radiocarbon 40 (1998) 1117-1125.
[48] S. Baumgartner, J. Beer, G. Wagner, P. Kubik, M. Suter, G.M. Raisbeck, F. Yiou, ${ }^{10} \mathrm{Be}$ and dust, Nucl. Instr. Methods B 123 (1997) 296-301.

[49] G. Wagner, Die kosmogenen Radionuklide ${ }^{10} \mathrm{Be}$ und ${ }^{36} \mathrm{Cl}$ im Summit-GRIP-Eisbohrkern, Ph.D. thesis, ETH, Zürich, 1998.

[50] M. Stuiver, H.A. Polach, Reporting ${ }^{14} \mathrm{C}$ data, Radiocarbon 19 (1977) 355-363. 